\title{
PREDICTION MODEL OF AIR-BORNE SALT DISTRIBUTION IN THE COASTAL REGION OF NORTHERN TAIWAN
}

\author{
Yu-Sheng Chen \\ Taiwan Construction Research Institute, Taipei, Taiwan, R.O.C., yschen@tcri.org.tw \\ Hui-Jen Chiu \\ Department of Civil Engineering, National Taiwan University, Taipei, Taiwan, R.O.C. \\ Yi-Wen Chan \\ Department of Civil Engineering, National Taiwan University, Taipei, Taiwan, R.O.C. \\ Yung-Chang Chang \\ Taiwan Construction Research Institute, Taipei, Taiwan, R.O.C. \\ Chung-Chia Yang \\ Institute of Materials Engineering, National Taiwan Ocean University, Keelung, Taiwan, R.O.C.
}

Follow this and additional works at: https://jmstt.ntou.edu.tw/journal

Part of the Civil and Environmental Engineering Commons

\section{Recommended Citation}

Chen, Yu-Sheng; Chiu, Hui-Jen; Chan, Yi-Wen; Chang, Yung-Chang; and Yang, Chung-Chia (2012) "PREDICTION MODEL OF AIR-BORNE SALT DISTRIBUTION IN THE COASTAL REGION OF NORTHERN TAIWAN," Journal of Marine Science and Technology. Vol. 20: Iss. 3, Article 3.

DOI: 10.51400/2709-6998.1802

Available at: https://jmstt.ntou.edu.tw/journal/vol20/iss3/3

This Research Article is brought to you for free and open access by Journal of Marine Science and Technology. It has been accepted for inclusion in Journal of Marine Science and Technology by an authorized editor of Journal of Marine Science and Technology. 


\section{PREDICTION MODEL OF AIR-BORNE SALT DISTRIBUTION IN THE COASTAL}

REGION OF NORTHERN TAIWAN

\section{Acknowledgements}

This study was sponsored by the Directorate General of Highways, M.O.T.C with the project expenditure for the "Research on the environmental air-borne salt and the corrosion of the bridges in North Taiwan". We are indebted to express our acknowledgements. 


\title{
PREDICTION MODEL OF AIR-BORNE SALT DISTRIBUTION IN THE COASTAL REGION OF NORTHERN TAIWAN
}

\author{
Yu-Sheng Chen ${ }^{1}$, Hui-Jen Chiu ${ }^{2}$, Yi-Wen Chan ${ }^{2}$, Yung-Chang Chang ${ }^{1}$, and \\ Chung-Chia Yang ${ }^{3}$
}

Key words: air-borne salt, reinforced concrete, prediction model, chloride.

\begin{abstract}
Taiwan is located in subtropical region, where temperature and humidity are relatively high all year round. Besides, the island is surrounded by ocean that the air-borne salt (ABS) attack is one of the major concerns for concrete structures. In this paper, a prediction model for the distribution of air-borne salt in the coastal region of northern Taiwan is proposed based on the result of ABS measurement at 38 sites near a period of four years. The ABS content was calculated monthly based on the salt concentration, water amount, time, and area of entrance. The monthly measured ABS of the entire year were then analyzed to obtain the characteristics of ABS attack in different conditions. By using the measurements of Chin-Shan, Keelung, and Lung-Fong sites, 480 data in total were analyzed by the proposed prediction model. The distance to seashore, wind direction, effective wind velocity, and effective precipitation are the primary factors for the ABS distribution.
\end{abstract}

\section{INTRODUCTION}

Durability of offshore or marine structures has been controlled by the corrosion of reinforcement mostly due to the air-borne salt (ABS) attach. To maintain such coastal structures or to prevent substantial corrosion requires tremendous cost that it has taken up a significant portion of infrastructurerelated budget for most of the developed countries. Therefore, experimental study or measurements of these environmental parameters become the very first step to establish a sound

Paper submitted 03/25/11; revised 05/12/11; accepted 09/01/11. Author for correspondence: Yu-Sheng Chen (e-mail: yschen@tcri.org.tw).

${ }^{1}$ Taiwan Construction Research Institute, Taipei, Taiwan, R.O.C.

${ }^{2}$ Department of Civil Engineering, National Taiwan University, Taipei, Taiwan, R.O.C.

${ }^{3}$ Institute of Materials Engineering, National Taiwan Ocean University, Keelung, Taiwan, R.O.C. correlation between structure performance and environmental factors. Conventional approach for durability design is to provide adequate protection layer of concrete. The provisions of existed design code on this regard have been based on empirical correlation, in which the extent of influence of chloride ion from the environment has not been verified.

Just like the earthquakes normally occur in seismic belts, the corrosion of reinforce concrete structures is also geographic-dependent. If we can have a better control of all the environmental factors just like what we have done for seismic design, we will not only be able to design and evaluate the structure more accurately, but also estimate the life-cycle cost of the structure correctly. It can also help to come up with a more effective policy to prevent the corrosion of reinforce concrete structures depending on the regional conditions, in order to minimize the maintenance costs. So the purpose of this study is to investigate the characteristics of ABS distribution along the northern Taiwan and to analyze the effect of meteorologic parameters, climate, and prevailing wind, so as to establish the domestic prediction model of ABS. Then one would be able to predict the different extent of salt attach at different region. As a result, concrete structures at different ABS zone will be subjected to different cover thickness or maximum water-to-cement ratio. It is expected, with the ABS contour (or zone), the design of RC structures along coastal region of northern Taiwan may be carried out.

\section{LITERATURE REVIEW}

The mechanism of ABS transportation is the phenomenon of the seawater moisture from splashed sea waves being carried to the land by the wind. The salt in the moisture, therefore, becomes the ABS. The ABS is transported along the coastal area and rests on the surface of concrete structures. The salt cumulated in the cover and infiltrates into the concrete structures. The concentration of ABS is closely related to the wind velocity as wind with higher speed may carry more salt to a longer distance. It has been reported that the distribution of ABS is closely related to the wind velocity, distance from the coastal line, and humidity of the region. Fig. 1 shows the 


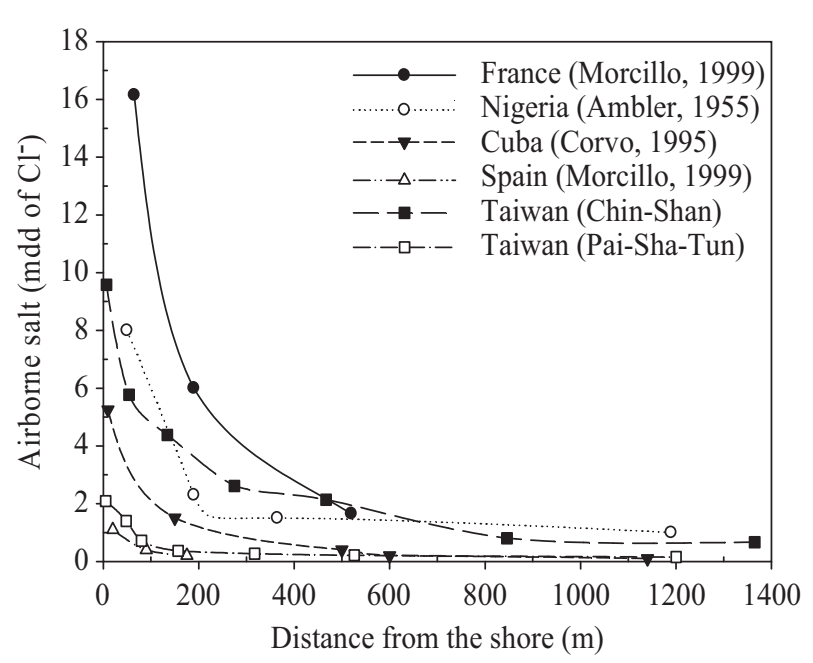

Fig. 1. Relationship between ABS and the distance from the shore of various countries $[3,4,8]$.

distribution of salt along the distance from the shore. The concentration of chloride ion in concrete reduces as much as $70 \%$ at a distance of $100 \mathrm{~m}$ from the shore [6]. It also shows that the decay curves of ABS content are very different in different country, even at two different places in Taiwan.

The Building Authority of Japan conducted a research program by measuring the concentration of ABS at 34 sites. The average salt concentration at different distance to the sea is given in Fig. 2. The result was employed to determine the $C_{\text {air }}$ value [7].

1. The results were analyzed along with the meteorologic records obtained in neighbor monitoring sites of the Weather Bureau. However, the differences in elevation and distance to the sea between weather monitoring sites and air-borne salt measurement was neglected.

2. In the analysis of air-borne salt, the following factors were also neglected, such as geological characteristics of coastal bedrock, topology of seashore, number of typhoons, buildings around the measuring sites, etc.

Based on the above result, the correlation between ABS concentration and distance to the sea can be established as following [1].

$$
C_{\text {air }}=1.29 \cdot r \cdot u^{0.386} \cdot d^{-0.952}
$$

in which " $r$ " being the wind ratio, namely the ratio of time of the wind within the angle of $\pm 45^{\circ}$, " $u$ " being the average wind velocity within the period of measurement (in $\mathrm{m} / \mathrm{s}$ ), and " $d$ " being the distance to the coastal line (in $\mathrm{km}$ ).

The above equation shows the decrease of ABS content with the distance to the sea. In fact, there are a number of factors that may affect the distribution of ABS content that the above equation does not account. Most of these factors are domestic parameters. The result proposed by above shown

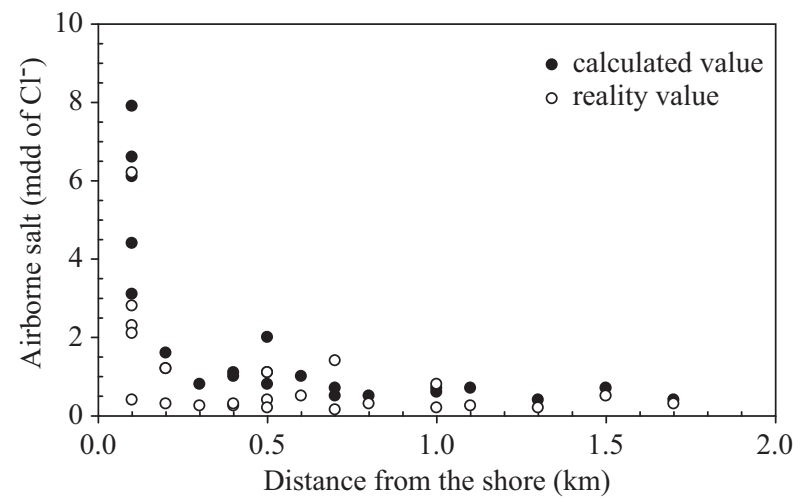

Fig. 2. Correlation between Cair and distance [7].

investigation may not apply in the case of Taiwan. Therefore, independent measurement and investigation on ABS is needed.

\section{PROGRAM OF IN-FIELD AIR-BORNE SALT MEASUREMENT}

The distribution of ABS in different regions may vary from site to site due to wind velocity, wind direction, precipitation, geological characteristics of seashore, etc. The more the number of measurement sites is, the more comprehensive the outcome would be. In this investigation program, a total number of 38 measurement sites were installed to measure the ABS in the field. The distance to the seashore, the elevation, and the prevailing wind directions are the major factors in selecting the measurement sites.

\section{Measuring Sites for $\mathrm{ABS}$}

For each location, there were a series of measuring sites being installed along the path perpendicular to the seashore. Three locations were selected, namely Chin-Shan (Taipei), Chu-Wei (Taoyuan), and Pai-Sha-Tun (Miaoli), representing the north, western north, and west of Taiwan coastal line, respectively. Totally 8 measuring sites were installed at 0,50 $\mathrm{m}, 100 \mathrm{~m}, 150 \mathrm{~m}, 250 \mathrm{~m}, 500 \mathrm{~m}, 1,000 \mathrm{~m}$, and 3,000 m from the shore at each location. Besides these three locations, there are five more supplementary locations, which set two measuring sites each. Fig. 3 shows the layout of all measuring sites.

In order to investigate the effects of direction of seashore and prevailing wind direction, 4-direction ABS capture devices were specially installed in NTOU and Chu-Wei area. And in order to investigate the effects of elevation, two ABS capture devices were specially installed in the elevation of 0 and $20 \mathrm{~m}$ at NTOU and Chin-Shan area. The distance, the angle and the elevation of devices are shown in Table 1.

\section{Air-Borne Salt Capture Device and Installation}

The ABS capture device developed by the Institute of Japan Civil Engineering, was adopted in this investigation program. Fig. 4 is a schematic illustration of the device. In principle, the direction of ABS capture device paralleled the sea shore. 
Table 1. The information for the ABS capture devices.

\begin{tabular}{|l|c|c|c|c|c|}
\hline \multicolumn{1}{|c|}{ Area } & Abbreviation & Num. & Distance $(\mathrm{m})$ & Angle $\left(^{\circ}\right)$ & Elevation $(\mathrm{m})$ \\
\hline Keelung NTOU & KN & 3 & 45,448 & $30,120,210,300$ & 0,20 \\
\hline Taipei Chin-Shan & CS & 9 & $19,54,134,275,467,846,1365,2546$ & 45 & 0,21 \\
\hline Taipei San-Chi & SC & 2 & 21,418 & 355 & - \\
\hline Chu-wei Fishing Port & CW & 10 & $11,39,88,330,495,648,912,2851,8469$ & $45,135,225,315$ & - \\
\hline Yong-An Fishing Port & YA & 2 & 150,550 & 310 & - \\
\hline HsinChu Fishing Port & HC & 2 & 15,267 & 300 & - \\
\hline Lung-Fong Fishing Port & LF & 2 & 11,445 & 290 & - \\
\hline Pai-Sha-Tun Fishing Port & PST & 8 & $3,48,80,157,317,526,1200,2753$ & 270 & - \\
\hline
\end{tabular}

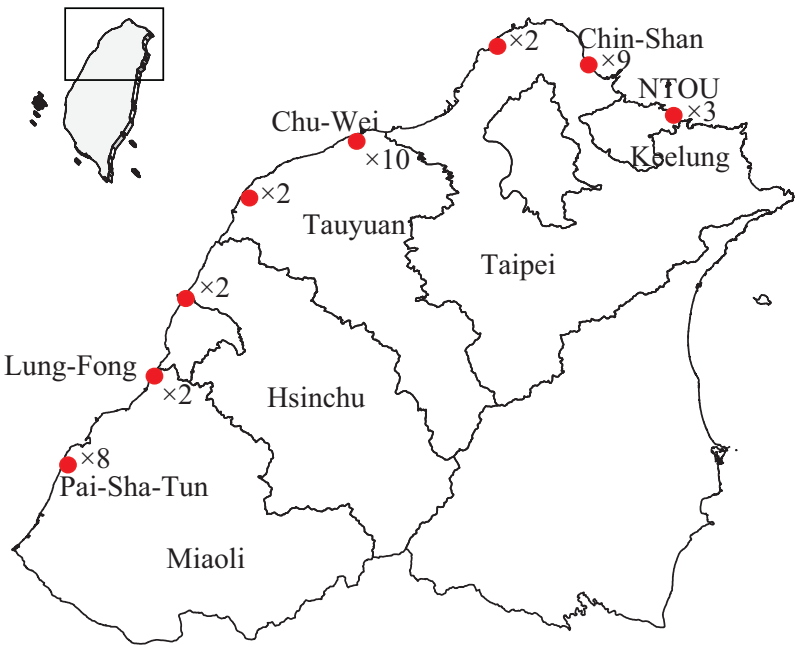

Fig. 3. Layout of ABS measuring sites.
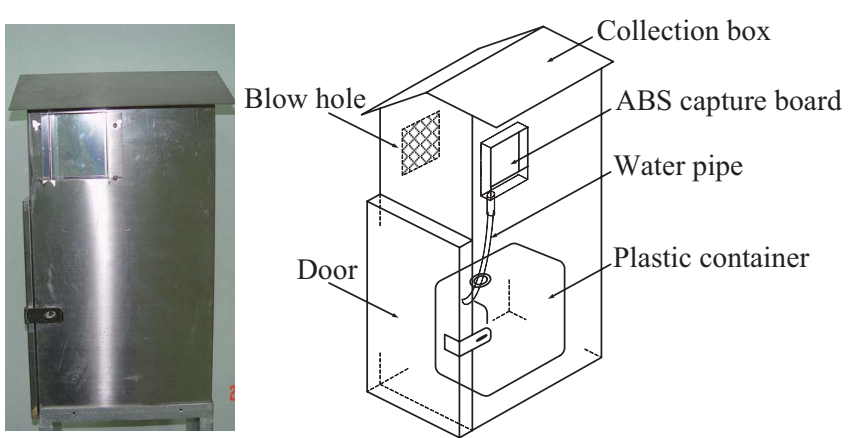

Fig. 4. ABS capture device by Japan Civil Engineering [3].

When sampling it, the salt adhering on the capture board and the gutter is washing into the plastic container by deionized water. Then all water in the container is weighed and taken some into the small bottle. Fig. 5 shows how these devices were installed at the measuring sites. The right side of this figure is an assembling of 4 devices that is capable of capturing ABS from 4 different directions.

The captured ABS was measured periodically for every month. By CNS 14702 A3384 electronic-titration method, the content of captured ABS can be calculated from the water in

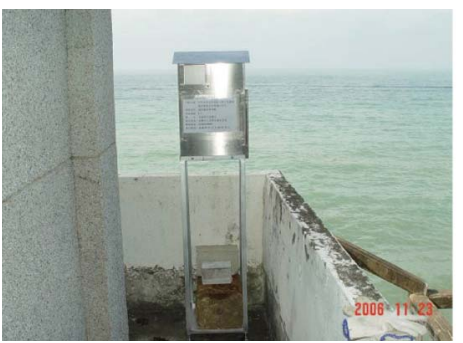

(a) Location: San-Chi

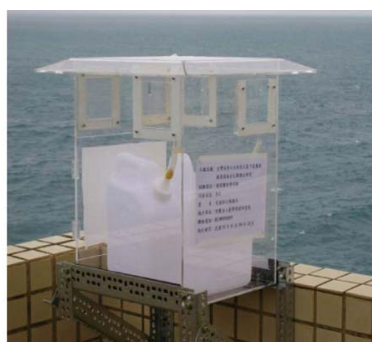

(b) Location: Keelung (NTOU)

Fig. 5. Installation of ABS capture devices.

the container of the device. The content of ABS is calculated based on the salt concentration, water amount, time, and area of entrance. The following equation can be used to resolve the ABS content as captured within the given period of time.

$$
A B S(m d d)=\frac{C \times W}{T \times A}
$$

in which $C$ : the concentration $(m g / m l)$;

$W$ : the water content $(m l)$;

$T$ : the time (day);

$A$ : the area $\left(d m^{2}\right)$;

$m d d=1 \mathrm{mg} / \mathrm{dm}^{2} /$ day

$d m^{2}=100 \mathrm{~cm}^{2}$

\section{RESULTS AND DISCUSSION}

\section{Distribution of ABS}

From December 2006 to August 2010, there were 45 investigations of ABS sampling finished. Table 2 shows the testing results of the locations that selected from coastal areas, and each seasonal data is derived from the average of three months.

From the Fig. 6, it is found the trend that the distribution of the ABS changes with different seasons. Even it's in a small area from Miaoli to Keelung, the distribution characteristics of ABS were still quite different, and the seasonal effects will be different also. In all regions the ABS reaches its high in 
Table 2. The results of ABS on the coastal spots of each area.

\begin{tabular}{|l|c|c|c|c|c|c|c|c|}
\hline Season & KN & CS & SC & CW & YA & HC & LF & PST \\
\hline 2006 winter & 3.48 & 12.38 & 7.98 & 4.13 & 0.27 & 0.29 & 0.56 & 0.66 \\
\hline 2007 spring & 1.88 & 5.75 & 3.34 & 1.37 & 0.85 & 0.88 & 1.02 & 0.96 \\
\hline 2007 summer & 0.72 & 1.19 & 0.30 & 0.07 & 1.32 & 0.97 & 1.09 & 1.81 \\
\hline 2007 autumn & 5.93 & 23.42 & 16.58 & 6.83 & 4.60 & 1.96 & 2.40 & 5.77 \\
\hline 2007 winter & 3.77 & 15.58 & 5.86 & 5.69 & 0.57 & 0.69 & 0.31 & 0.97 \\
\hline 2008 spring & 1.02 & 3.05 & 0.89 & 1.46 & 0.70 & 0.58 & 0.59 & 0.92 \\
\hline 2008 summer & 0.80 & 0.29 & 0.47 & 0.27 & 1.07 & 1.14 & 1.67 & 4.13 \\
\hline 2008 autumn & 5.50 & 22.99 & 2.51 & 5.67 & 0.18 & 0.25 & 2.34 & 3.54 \\
\hline 2008 winter & 4.41 & 16.33 & 7.12 & 4.68 & 0.63 & 0.68 & 0.41 & 0.60 \\
\hline 2009 spring & 2.25 & 4.08 & 0.79 & 2.04 & 0.27 & 0.25 & 0.37 & 0.73 \\
\hline 2009 summer & 0.47 & 0.30 & 0.50 & 0.23 & 2.06 & 1.65 & 1.90 & 2.84 \\
\hline 2009 autumn & 6.98 & 23.09 & 2.94 & 3.32 & 0.85 & 0.82 & 1.86 & 1.42 \\
\hline 2009 winter & 4.45 & 11.89 & 3.29 & 4.36 & 0.98 & 0.94 & 0.70 & 1.50 \\
\hline 2010 spring & 2.51 & 4.13 & 1.20 & 1.80 & 0.62 & 0.44 & 0.52 & 0.65 \\
\hline 2010 summer & 0.40 & 0.41 & 0.42 & 0.50 & 1.97 & 1.49 & 1.11 & 1.96 \\
\hline
\end{tabular}

Note: The unit for ABS is $m d d$.

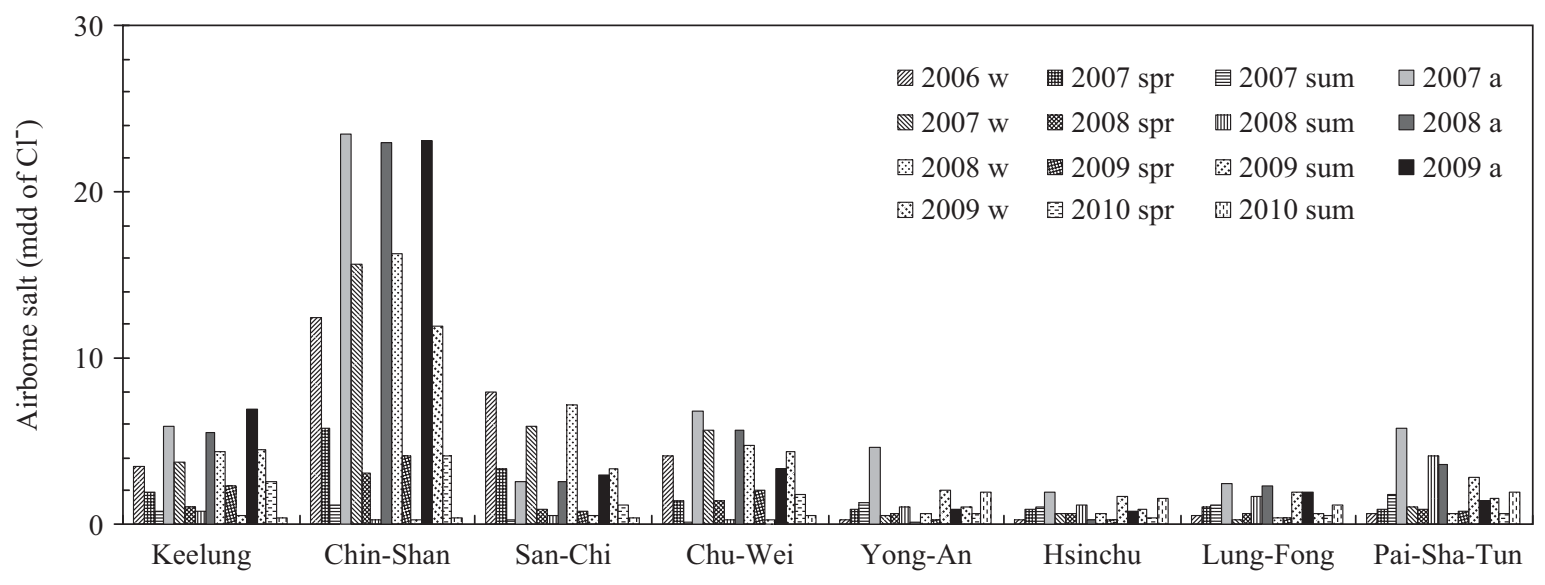

Fig. 6. ABS distribution of measuring site by seashore of each location in different seasons.

autumn (September, October, and November). It's mainly affected by the frequent typhoons in autumn. However, in the area from Keelung to Chu-wei, the content of ABS in winter (December, January, and February) is much more than the ABS in spring (March, April, and May) as well as summer (June, July, and August). It is supposed to be subject to the effects of the northeast monsoon in winter. As for the area from Chu-wei to Miaoli, the ABS in spring and summer are both higher than it is in winter, which is affected by the southwest monsoon. Therefore, the distribution trend changes with the shift of directions of monsoon. In addition, the seasonal distribution statuses of the ABS in every sampling locations list in Fig. 6 mostly shows a considerably high reproducibility, which means the content of ABS in every seasons are quite close as well as indicates that the investigation conclusions in this study are highly referable.
Fig. 7 shows the curve of the seasonal distribution of the ABS at Chin-Shan, Chu-Wei and Pai-Sha-Tun area. It can be found from the figure that there are significant differences of the ABS in different seasons. For example, in Chin-Shan area, the ABS in autumn and winter is much higher than it is in spring and summer, in which the differences can be decuples. Moreover, the amount of ABS is also relevant to the distance away from the coastline. The amount of ABS collected from each measuring sites declines as the distance gains. When the distance away from the coastline is more than $500 \mathrm{~m}$, the amount of ASB in each season declines to only $13 \%$ to $28 \%$ of the amount collected on coastal sites. And when the distance away from the coastline is more than $1200 \mathrm{~m}$, the amount of ABS approximates to a stable and relatively small value. The same trend is also found in Chu-Wei and Pai-Sha-Tun area in this study. 


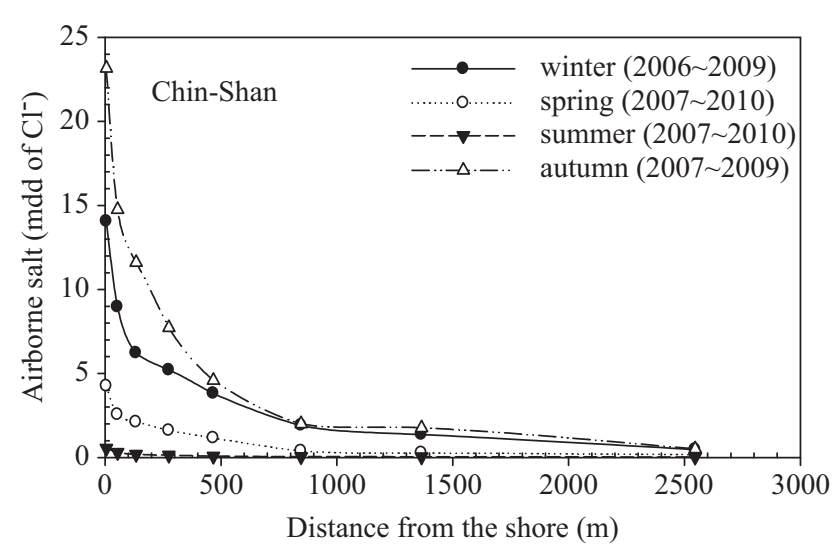

(a) Chin-Shan

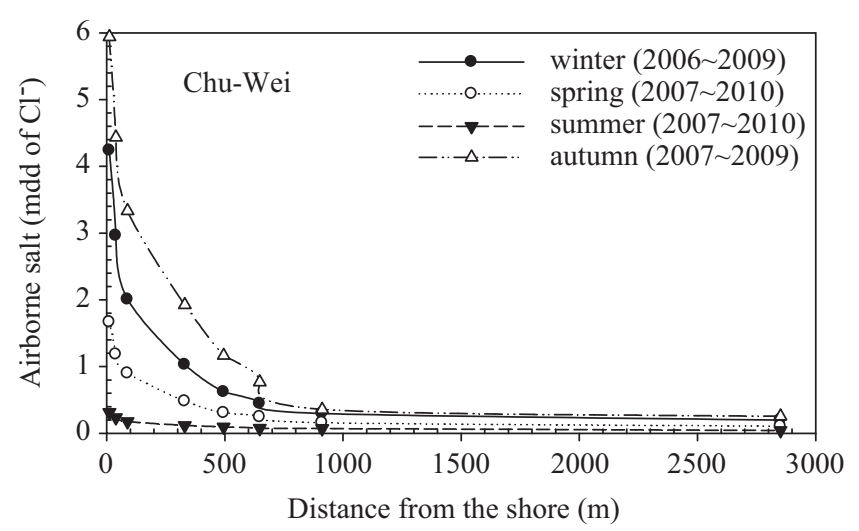

(b) Chu-Wei

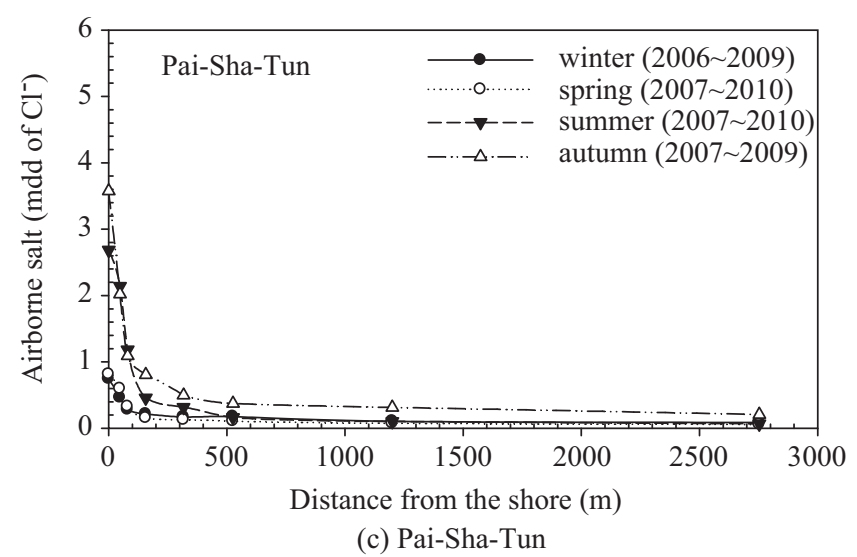

Fig. 7. The distribution of $\mathrm{ABS}$ in various seasons at three different area.

\section{Influence of Meteorologic Parameters}

The influence of meteorologic parameters to the ABS distribution was so obvious that various meteorologic records were included in analysis of this study. The factors considered included wind direction, wind velocity, and precipitation. The influence of meteorologic parameters was then considered by modifying the characteristics of ABS distribution accordingly. The meteorologic records were available from the Central Weather Bureau and Environmental Protection Administration respectively.

Since the installation of ABS capture devices is with certain

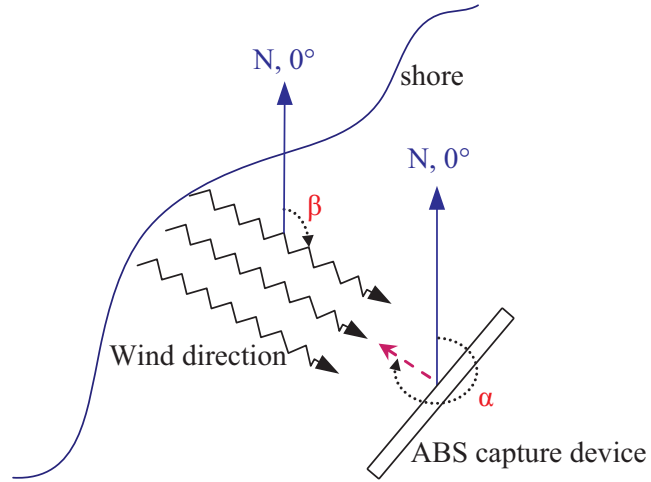

Fig. 8. The diagram of the transformed of meteorologic parameters.

direction requirement, the wind direction, velocity, or precipitation would not necessarily affect the device in all cases. Therefore in this study the relationship between the wind directions and the installation directions of ABS capture devices will be considered and modified when taking the meteorologic data into account. Firstly, the data of wind direction were analyzed to acquire the effective ratio of the wind direction to the device, which is the percentage of the samedirection rate between the hourly wind direction and the device. The modified formula is shown as Eq. (3). Afterward, analyze the wind velocity and precipitation data by comparing the wind direction at that time, and modify the angle of the sampler following the analysis results. In this way the adopted assumption is that the wind velocity and precipitation only affect the sampling of ABS when they are within the range of $180^{\circ}$. The modified wind velocity and precipitation are effective wind velocity and effective precipitation, and the modified formulas are shown as Eqs. (4) and (5).

Effective wind direction: $r=\frac{\sum_{j=1}^{30} \sum_{i=1}^{24}\left|\cos \left(\beta_{j i}-\alpha_{j i}\right)\right|}{j \times i} \times 100 \%$

Effective wind velocity: $u_{r}=\frac{\sum_{j=1}^{30} \sum_{i=1}^{24}\left|u_{j i} \times \cos \left(\beta_{j i}-\alpha_{j i}\right)\right|}{j \times i}$

Effective precipitation: $w_{r}=\sum_{j=1}^{30} \sum_{i=1}^{24}\left|w_{j i} \times \cos \left(\beta_{j i}-\alpha_{j i}\right)\right|$

In which,

$\alpha$ : the angle of capture device, as shown in Fig. 8;

$\beta$ : the wind direction angle according to the Weather $\mathrm{Bu}-$ reau, as shown in Fig. 8;

$u_{j i}$ : the original hourly wind velocity provided by the Weather Bureau $(\mathrm{m} / \mathrm{sec})$;

$w_{j i}$ : the original hourly precipitation provided by the Weather Bureau $(\mathrm{mm})$;

$i$ : the number of hour;

$j$ : the number of day 
Table 3. Meteorologic records of various directions (Keelung).

\begin{tabular}{|c|c|c|c|c|c|c|c|c|c|c|c|c|}
\hline \multirow{2}{*}{ Season } & \multicolumn{4}{|c|}{ Eff. Wind direction $(\%)$} & \multicolumn{4}{|c|}{ Eff. wind velocity $(\mathrm{m} / \mathrm{s})$} & \multicolumn{4}{|c|}{ Eff. Precipitation $(\mathrm{mm})$} \\
\hline & $30^{\circ}$ & $120^{\circ}$ & $210^{\circ}$ & $300^{\circ}$ & $30^{\circ}$ & $120^{\circ}$ & $210^{\circ}$ & $300^{\circ}$ & $30^{\circ}$ & $120^{\circ}$ & $210^{\circ}$ & $300^{\circ}$ \\
\hline 07 winter & 42.5 & 64.7 & 9.1 & 15.9 & 0.86 & 1.46 & 0.57 & 0.76 & 237 & 410 & 22 & 29 \\
\hline 08 spring & 33.5 & 46.6 & 18.9 & 31.9 & 0.72 & 1.24 & 0.57 & 0.68 & 103 & 131 & 37 & 63 \\
\hline 08 summer & 23.9 & 35.3 & 34.5 & 36.6 & 0.95 & 1.49 & 0.84 & 0.80 & 35 & 67 & 23 & 13 \\
\hline 08 autumn & 37.7 & 58.8 & 15.7 & 20.3 & 0.96 & 1.54 & 0.56 & 0.66 & 196 & 326 & 92 & 90 \\
\hline 08 winter & 38.3 & 57.3 & 14.3 & 22.3 & 0.79 & 1.27 & 0.44 & 0.59 & 142 & 230 & 32 & 38 \\
\hline 09 spring & 34.8 & 51.7 & 18.5 & 25.4 & 0.88 & 1.39 & 0.59 & 0.66 & 56 & 95 & 36 & 23 \\
\hline 09 summer & 23.3 & 37.0 & 34.0 & 36.0 & 0.90 & 1.52 & 0.83 & 0.78 & 38 & 69 & 56 & 39 \\
\hline 09 autumn & 40.3 & 64.2 & 10.4 & 17.6 & 0.95 & 1.54 & 0.59 & 0.77 & 201 & 306 & 30 & 42 \\
\hline 09 winter & 38.4 & 53.0 & 14.9 & 26.0 & 0.79 & 1.32 & 0.49 & 0.62 & 173 & 278 & 19 & 32 \\
\hline 10 spring & 36.6 & 44.9 & 18.2 & 31.0 & 0.70 & 1.13 & 0.55 & 0.65 & 59 & 94 & 36 & 58 \\
\hline 10 summer & 25.2 & 35.9 & 28.7 & 39.9 & 0.92 & 1.86 & 1.05 & 0.95 & 41 & 59 & 72 & 79 \\
\hline
\end{tabular}

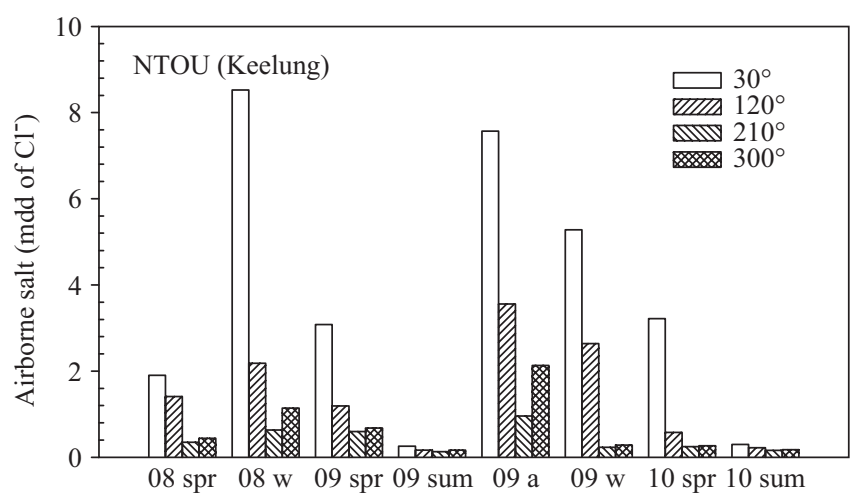

Fig. 9. ABS distribution of 4 different directions at measuring site of NTOU (Keelung).

\section{Influence by Direction of ABS Capture Device}

As shown in Fig. 5, a 4-direction capture device was installed at the measuring site of NTOU. The capture device was arranged in this way to capture ABS from four different directions to investigate the influence of direction. At the site of NTOU, the normal direction of seashore is at $30^{\circ}$. As a result, it is found that the $\mathrm{ABS}$ content is the highest at $30^{\circ}$ as shown in Fig. 9. The ABS content obtained from $120^{\circ}$ is next to it. However, the meteorologic records including wind direction, wind velocity and precipitation of $120^{\circ}$ is higher than $30^{\circ}$ as shown in Table 3 . This finding can be explained by Fig. 10. It shows that the NTOU site exposes to the sea at a wide angle of more than $180^{\circ}$. Wind from this range of angle would have carried ABS to the capture device. On the reverse direction to the seashore, on the other hand, the ABS carried to the capture device is significantly less than those from the other 3 directions. This observation suggests that, given the same geological condition, the influence of prevailing wind direction, wind velocity, and precipitation may have critical effects to the ABS distribution in the coastal region.

\section{Influence of Elevation}

In addition, the result of measurement at different eleva-

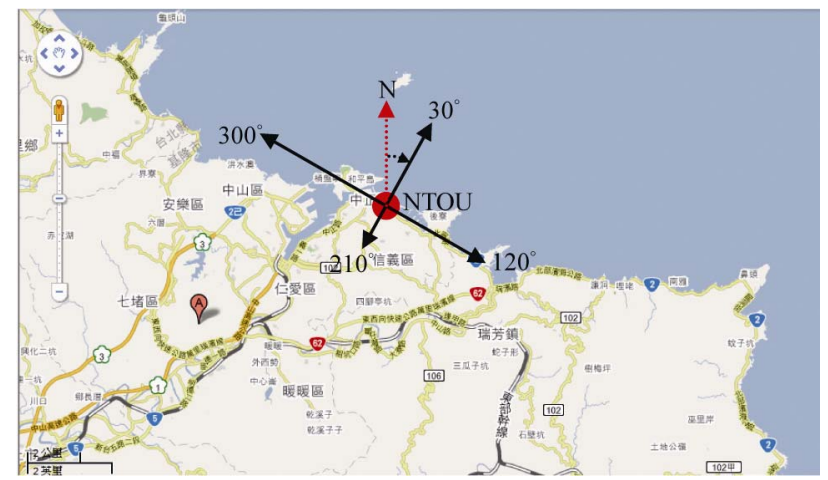

Fig. 10. Location of NTOU (Keelung) measuring site (from google map).

tions indicates different trends in different seasons as shown in Fig. 11. This suggests that elevation along may not be an individual factor for the ABS distribution. For example, the result in Keelung is that the higher area the higher content of ABS. But the result in Chin-Shan is that higher area the lower content of ABS. It can be related to wind or geological conditions. So in this study, the relationship between the content of $\mathrm{ABS}$ and the elevation of the measuring site is not quite obvious.

\section{Prediction Model for ABS Content}

In order to establish the correlation between ABS distribution and meteorologic parameters, a measuring site near the weather monitoring station of Chin-Shan was selected to collect representing information on this issue. The distance between ABS measuring site and the weather monitoring station is only $0.76 \mathrm{~km}$. In Table 4, the effective wind direction $r$, effective wind velocity $u_{r}$, and effective precipitation $w_{r}$ were used as the factors for regression by different combinations.

The coefficients of correlation for each combination are shown in Table 4. Fig. 12 shows the measured ABS content and predicted values by regression equations. The statistics method is ordinary least squares (OLS) by STATA software [0]. The coefficients of factor for each regression equation are 
Table 4. The coefficients of correlation and F-value.

\begin{tabular}{|c|c|c|c|c|c|c|}
\hline Item & Factor & Regression equation & $\mathrm{R}^{2}$ & Adj. $\mathrm{R}^{2}$ & F-value & Pro $>\mathrm{F}$ \\
\hline 1 & $r$ & $C_{a i r}=\mathrm{a} \times r^{\mathrm{b}}$ & 0.438 & 0.423 & 28.86 & 0.000 \\
\hline 2 & $u_{r}$ & $C_{a i r}=\mathrm{a} \times u_{r}{ }^{\mathrm{b}}$ & 0.676 & 0.667 & 77.12 & 0.000 \\
\hline 3 & $w_{r}$ & $C_{a i r}=\mathrm{a} \times w_{r}{ }^{2}+\mathrm{b} \times w_{r}$ & 0.785 & 0.773 & 65.81 & 0.000 \\
\hline 4 & $r \cdot u_{r}$ & $C_{a i r}=\mathrm{a} \times r^{\mathrm{b}} \times u_{r}{ }^{\mathrm{c}}$ & 0.768 & 0.755 & 59.65 & 0.000 \\
\hline 5 & $r \cdot w_{r}$ & $C_{a i r}=\mathrm{a} \times r^{\mathrm{b}} \times w_{r}{ }^{\mathrm{c}}$ & 0.625 & 0.604 & 30.03 & 0.000 \\
\hline 6 & $u_{r} \cdot w_{r}$ & $C_{a i r}=\mathrm{a} \times u_{r}^{\mathrm{b}} \times w_{r}{ }^{\mathrm{c}}$ & 0.814 & 0.804 & 78.79 & 0.000 \\
\hline 7 & $r \cdot u_{r} \cdot w_{r}$ & $C_{a i r}=\mathrm{a} \times r^{\mathrm{b}} \times u_{r}^{\mathrm{c}} \times w_{r}{ }^{\mathrm{d}}$ & 0.841 & 0.827 & 61.51 & 0.000 \\
\hline
\end{tabular}

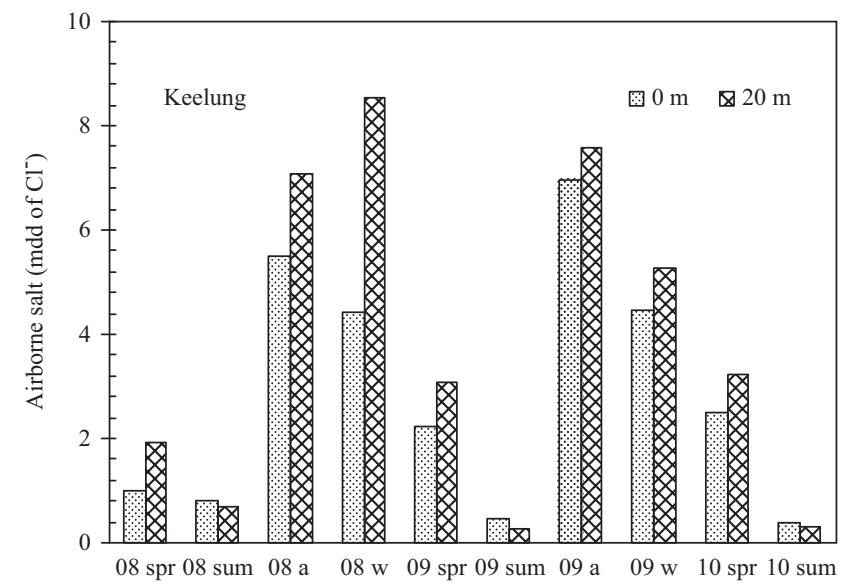
(a) Keelung

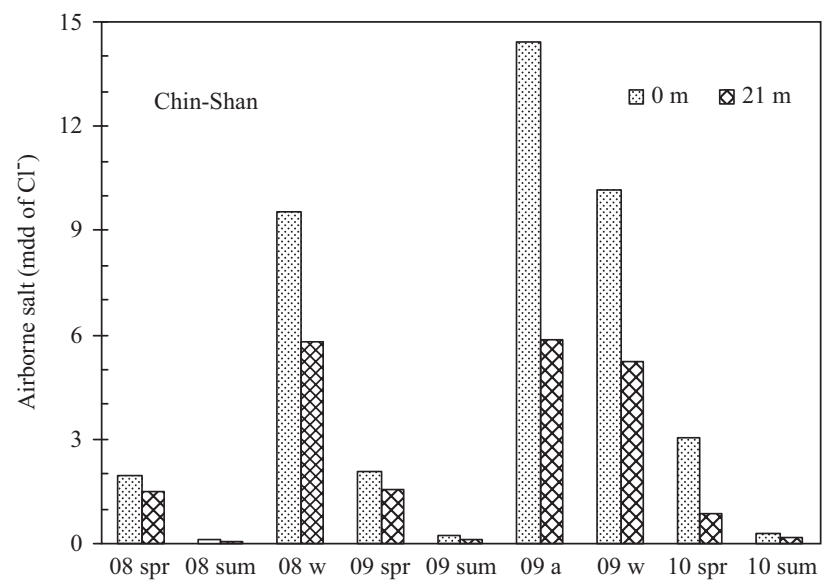

(b) Chin-Shan

Fig. 11. ABS distribution of different elevations.

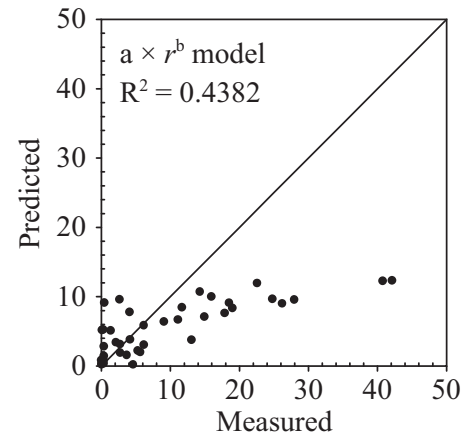

(a)

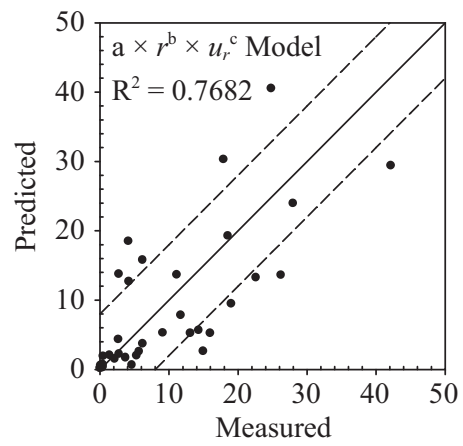

(d)

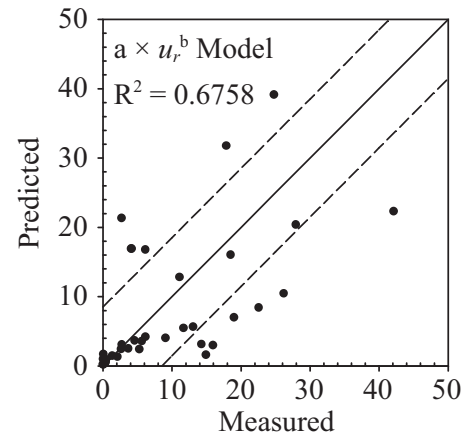

(b)

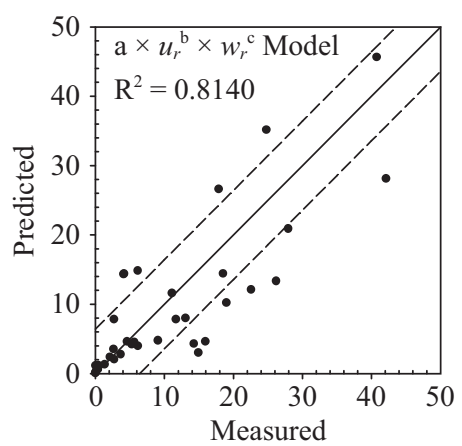

(e)

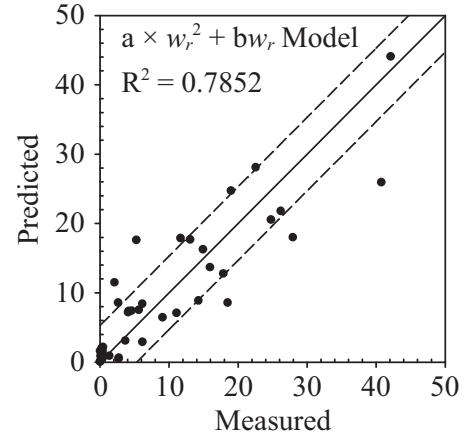

(c)

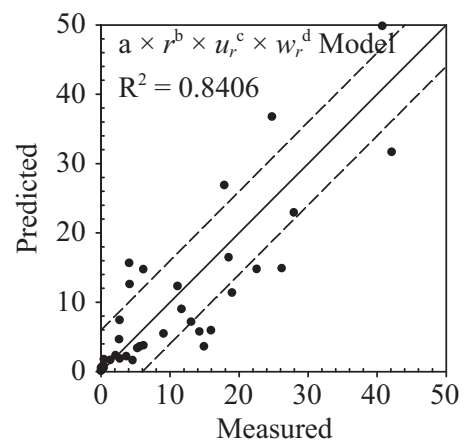

(f)

Fig. 12. Measured ABS content and predicted values by regression equations. 
Table 5. Regression equations and coefficients of factor.

\begin{tabular}{|c|c|c|c|c|c|}
\hline Item & Regression equation & & Coef. & $t$ & $P>|t|$ \\
\hline \multirow{2}{*}{1} & \multirow{2}{*}{$C_{a i r}=\mathrm{a} \times r^{\mathrm{b}}$} & $\mathrm{a}$ & $1.264 \mathrm{E}-5$ & -4.81 & 0.000 \\
\hline & & $\mathrm{b}$ & 3.196 & 5.37 & 0.000 \\
\hline \multirow{2}{*}{2} & \multirow{2}{*}{$C_{a i r}=\mathrm{a} \times u_{r}^{\mathrm{b}}$} & $\mathrm{a}$ & 1.281 & 1.20 & 0.237 \\
\hline & & $\mathrm{b}$ & 1.883 & 8.78 & 0.000 \\
\hline \multirow{2}{*}{3} & \multirow{2}{*}{$C_{a i r}=\mathrm{a} \times w_{r}^{2}+\mathrm{b} \times w_{r}$} & $\mathrm{a}$ & 0.000391 & 4.65 & 0.000 \\
\hline & & $\mathrm{b}$ & 0.005721 & 0.31 & 0.757 \\
\hline \multirow{3}{*}{4} & \multirow{3}{*}{$C_{a i r}=\mathrm{a} \times r^{\mathrm{b}} \times u_{r}^{\mathrm{c}}$} & $\mathrm{a}$ & $2.210 \mathrm{E}-3$ & -3.62 & 0.001 \\
\hline & & $\mathrm{b}$ & 1.674 & 3.79 & 0.001 \\
\hline & & $\mathrm{c}$ & 1.501 & 7.16 & 0.000 \\
\hline \multirow{3}{*}{5} & \multirow{3}{*}{$C_{a i r}=\mathrm{a} \times r^{\mathrm{b}} \times w_{r}^{\mathrm{c}}$} & $\mathrm{a}$ & $2.147 \mathrm{E}-4$ & -4.11 & 0.000 \\
\hline & & $\mathrm{b}$ & 1.795 & 3.03 & 0.005 \\
\hline & & $\mathrm{c}$ & 0.608 & 4.24 & 0.000 \\
\hline \multirow{3}{*}{6} & \multirow{3}{*}{$C_{a i r}=\mathrm{a} \times u_{r}^{\mathrm{b}} \times w_{r}{ }^{\mathrm{c}}$} & $\mathrm{a}$ & 0.187 & -4.15 & 0.000 \\
\hline & & $\mathrm{b}$ & 1.402 & 7.42 & 0.000 \\
\hline & & $\mathrm{c}$ & 0.498 & 5.17 & 0.000 \\
\hline \multirow{4}{*}{7} & \multirow{4}{*}{$C_{a i r}=\mathrm{a} \times r^{\mathrm{b}} \times u_{r}^{\mathrm{c}} \times w_{r}{ }^{\mathrm{d}}$} & $\mathrm{a}$ & $6.449 \mathrm{E}-3$ & -3.49 & 0.001 \\
\hline & & $\mathrm{b}$ & 0.989 & 2.41 & 0.021 \\
\hline & & $\mathrm{c}$ & 1.274 & 6.88 & 0.000 \\
\hline & & $\mathrm{d}$ & 0.397 & 3.99 & 0.000 \\
\hline
\end{tabular}

shown in Table 5. The $P$-value of each factor must be less than 0.05 . It means that the probability for error would be less than $5 \%$. If the $P$-value is higher than 0.05 , the model would not be take into consideration. It was found that two kind of combinations provided higher correlations. The coefficients of correlation are 0.814 and 0.841 respectively. The distinction is as follows:

- effective wind velocity $u_{r}+$ effective precipitation $w_{r}$;

- effective wind direction $r+$ effective wind velocity $u_{r}+$ effective precipitation $w_{r}$.

Besides, according to the measurements from Keelung and Lung-Fong sites, which are $3.32 \mathrm{~km}$ and $3.47 \mathrm{~km}$ to the weather monitoring station respectively, calculated coefficients of correlation by regression are 0.764 and 0.798 respectively, based on the previous two factor combinations as shown in Fig. 13. It suggests that the regression equations based on Chin-Shan data apply in the data from other measuring sites. However, the correctness or precision of prediction is related to the distance between ABS measuring site and weather monitoring station. The closer the weather monitoring station to the corresponding ABS measuring site, the higher the precision of the prediction would be. This is due to the fact that the local meteorologic parameters do have significant influence on ABS deposit characteristics.

Based on the previous regression equations, a prediction model of local ABS distribution can be obtained after incorporating the distance to the seashore as the major parameter as following.

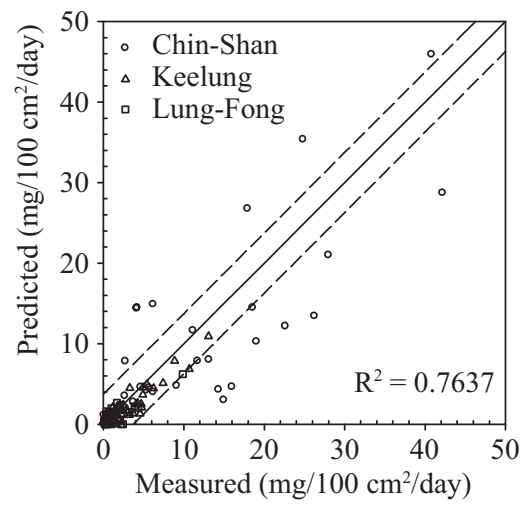

(a) $C_{a i r}=\mathrm{a} \times u_{r}^{\mathrm{b}} \times w_{r}^{\mathrm{c}}$

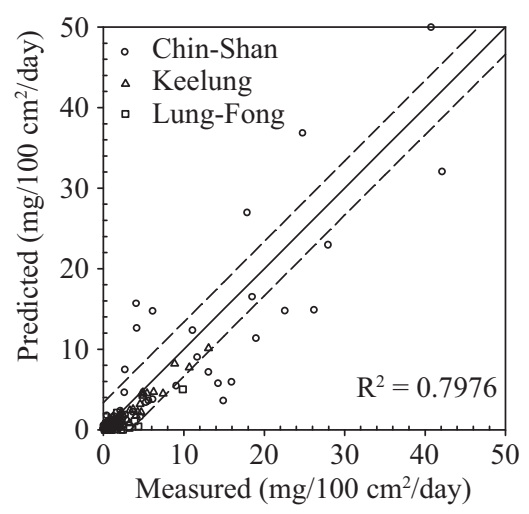

(b) $C_{\text {air }}=\mathrm{a} \times r^{\mathrm{b}} \times u_{r}^{\mathrm{c}} \times w_{r}^{\mathrm{d}}$

Fig. 13. Measured ABS content and predicted values by regression equations.

$$
C_{\text {air }}=0.05 \times r \times u_{r}^{1.27} \times w_{r}^{0.4} \times d^{-0.6}
$$

in which

$C_{\text {air }}$ : ABS content $\left(\mathrm{mg} / 100 \mathrm{~cm}^{2} /\right.$ day $)$;

$r$ : percentage of wind direction $(\%)$;

$u_{r}$ : effective wind velocity $(\mathrm{m} / \mathrm{sec})$;

$w_{r}$ : effective precipitation $(\mathrm{mm})$

$d$ : distance to the seashore $(\mathrm{km})$

By using the measurements of Chin-Shan, Keelung, and Lung-Fong sites, near 480 data in total were analyzed by the proposed prediction model. A coefficient of correlation of 0.76 was obtained as shown in Fig. 14, which is regarded as satisfactory given so many factors that may affect the ABS distribution. Table 6 shows the coefficient of factor and $P$-value which is less than 0.05 . Therefore, the distance to seashore, wind direction, effective wind velocity, and effective precipitation are the primary factors for the ABS distribution.

\section{Comparison}

Fig. 15 shows the relationship between measured ABS content and the distance from the shore in Chin-Shan in may 2009 of two prediction models. One is domestic prediction model in this study, and the other is Japanese's model. It shows that the calculated value of prediction model in this 
Table 6. Regression equations and coefficients of factor.

\begin{tabular}{|c|c|c|c|c|}
\hline Regression equation & \multicolumn{2}{|c|}{ Coef. } & $t$ & $P>|t|$ \\
\hline \multirow{3}{*}{$C_{a i r}=\mathrm{a} \times r^{\mathrm{b}} \times u_{r}{ }^{\mathrm{c}} \times w_{r}{ }^{\mathrm{d}} \times d^{\mathrm{e}}$} & $\mathrm{a}$ & 0.0502 & -3.78 & 0.002 \\
\cline { 2 - 5 } & $\mathrm{b}$ & 0.987 & 2.46 & 0.023 \\
\cline { 2 - 5 } & $\mathrm{c}$ & 1.273 & 6.70 & 0.000 \\
\cline { 2 - 5 } & $\mathrm{d}$ & 0.397 & 3.95 & 0.000 \\
\cline { 2 - 5 } & $\mathrm{e}$ & -0.605 & 7.31 & 0.000 \\
\hline
\end{tabular}

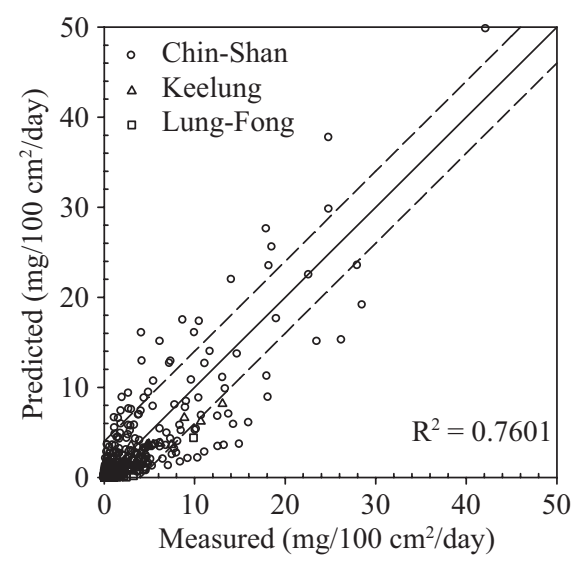

Fig. 14. Regression of ABS content by the primary factors.

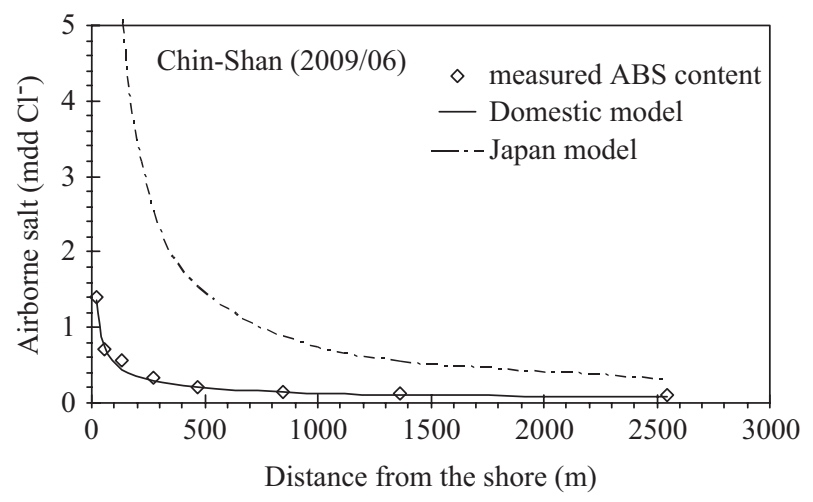

Fig. 15. Relationship between measured ABS and prediction models.

study is well closed to the measured one. The percentage of average error is about $12.2 \%$. However, the model of Japan comparatively has a larger error, more than decuple time. From this result, the domestic measurement and investigation on ABS is needed, and the effect of domestic prediction models is much better than foreign one.

\section{CONCLUSIONS AND PROPOSITIONS}

1. The results of in-field ABS measurements show that the trends of the distribution of yearly ABS are about the same. Values collected from each site are with significant reproducibility, which means the devices applied in this study are certainly applicable. The data from the tests also shows that the amount of ABS in the sampling sites is closely related to the distance and the direction to the seashore, and highly affected by the monsoon. The cumulated ABS decreases with the increase of distance to seashore. When the distance is farther than $1.2 \mathrm{~km}$, the ABS will be relatively lower.

2. The measurements from different elevation at the same site show that discrepancy in the effect of elevation on ABS distribution. It is found that the effect of elevation might be reverse in different seasons. It indicates that the elevation might not be an independent factor for ABS distribution. Some other factors, such as meteorologic parameters and local conditions, should be taken into account, as well.

3. The adopted capture device only receives ABS from a certain direction. The setup of capture device might be critical to what could be measured. If the direction does not correspond to the prevailing wind direction, the measured ABS content may not be the highest possible content at that particular measuring site. So it is suggested to apply the effective wind direction, effective wind velocity, and effective precipitation, and also the hourly meteorologic data for analysis, in order to establish the correlation between the meteorologic data and the amount of ABS.

4. In general, the proposed statistics prediction model provides an overall coefficient of correlation of 0.76 in regression when 480 measured data by this investigation program were used to analysis. It means the content of ABS can be expressed via the wind direction, wind velocity, precipitation and distance. So engineers could easily obtain the content of ABS in somewhere without measured data.

\section{ACKNOWLEDGMENTS}

This study was sponsored by the Directorate General of Highways, M.O.T.C with the project expenditure for the "Research on the environmental air-borne salt and the corrosion of the bridges in North Taiwan". We are indebted to express our acknowledgements.

\section{REFERENCES}

1. Akiyama, M., Ito, Y., and Suzuki, M., "A fundamental investigation on reliability of reinforced concrete structure in severe environments," Proceedings of JSCE Conventions, Vol. 62, No. 2, pp. 385-401 (2006).

2. Ambler, H. R. and Bain, A. A. J., "Corrosion of metals in the tropics," Journal of Applied Chemistry, Vol. 5, No. 9, pp. 437-467 (1955).

3. Chan, Y. W., Yang, C. C., Chen, Y. S., and Chang, Y. C., "Investigation on air-borne salt and corrosion of bridge structures in Northern Taiwan in severe environment," Research Report of General Highway Bureau, Taiwan (2010).

4. Corvo, F., Betancourt, N., and Mendoza, A., "The influence of airborne salinity on the atmospheric corrosion of steel," Corrosion Science, Vol. 37, No. 12, pp. 1889-1901 (1995).

5. Greene, W. H., Econometric Analysis, 5th Edition, Prentice-Hall, New Jersey (2003).

6. Meira, G. R., Andrade, C., Padaratz, I. J., Alonso, C., and Borba, J. C., "Chloride penetration into concrete structures in the marine atmosphere 
zone - Relationship between deposition of chlorides on the wet candle and chlorides accumulated into concrete," Journal of Cement \& Concrete Composites, Vol. 29, No. 9, pp. 667-676 (2007).

7. Mishikawa, K. and Tanaka, Y., "A nation-wise investigation of air-borne salt content (IV)," Division of Bridge Structures of Institute of Civil En- gineering, Ministry of Construction, No. 3175 (1993).

8. Morcillo, M., Chico, B., Otero, E., and Mariaca, L., "Effect of marine aerosol on atmospheric corrosion," Mater Perform, Vol. 38, No. 4, pp. 72-77 (1999). 